\title{
Potential for COVID-19 coronavirus (SARS-CoV-2) exposure during laparoscopic gynaecological surgery
}

\author{
Dr Graham S Taylor ${ }^{1}$, Dr Claire Shannon-Lowe ${ }^{1}$, Dr Heather M Long ${ }^{1}$, Prof Sudha Sundar ${ }^{2}$ \\ ${ }^{1}$ Institute of Immunology and Immunotherapy, University of Birmingham, Vincent Drive, \\ Birmingham, B15 2TT. United Kingdom \\ 2 Institute of Cancer and Genomic Sciences, University of Birmingham, Vincent Drive, \\ Birmingham, B15 2TT. United Kingdom
}

Correspondence: S.S.Sundar@bham.ac.uk; G.S.Taylor@bham.ac.uk

The potential for transmission of SARS-COV-2 during minimally invasive procedures, such as laparoscopy, is not known. Guidelines caution against use of laparoscopic surgery based on risks extrapolated from other viruses, on limited data and conflict with each other ${ }^{1,2}$. We examined existing data for prevalence of virus in the reproductive tract and other bodily fluids. A Medline search, $6^{\text {th }}$ April 2020 did not find any studies directly measuring the presence of infectious viral particles in the blood or reproductive tract. Several reports, however, describe results of various PCR-based assays to detect viral RNA in different sample types. In addition to upper and lower respiratory tract samples, SARS-CoV-2 RNA is present in a range of bodily specimens including faeces and blood ${ }^{3-8}$.

Infectious virions are essential for viral transmission and their quantity will influence transmission risk. Recent research studying patients with mild COVID-19 symptoms now shows SARS-CoV-2 RNA detection does not necessarily indicate infectious virus ${ }^{3}$. In respiratory samples, viral RNA was detected up to 13 days from symptom onset but infectious virus was only detected in samples from the first 8 days (and only in samples with high viral RNA levels) ${ }^{3}$. While viral RNA was detected for prolonged periods of time in stool samples, infectious virus was never detected even in samples with high viral RNA loads ${ }^{3}$.

The presence of viral RNA in the blood of COVID-19 patients raises the possibility of bloodborne transmission via accidental inoculation or aerosols generated during laparoscopic procedures. However, only a minority of COVID-19 patients have detectable viral RNA in the blood. Viral detection ranges from $0 \%{ }^{3}, 1 \%{ }^{5}, 8 \%{ }^{6}, 11.5 \%{ }^{7}$ to $15 \%{ }^{8}$ of patients. Using the number of PCR cycles to estimate viral RNA levels, the amount of viral RNA in blood is also low, over 1000 times lower than levels measured using nasal swabs which usually yield the highest levels of virus ${ }^{5}$.

Evidence of vertical transmission to newborns could indicate viral exposure to the infant from the reproductive organs during gestation or the reproductive tract if delivered vaginally. Three studies reporting 15 women who gave birth with active COVID-19 found no virus transmission to infants. Amniotic fluid, cord blood and breast milk were negative for the virus and vaginal swabs from two women were also negative ${ }^{9-11}$. A larger study of 33 infants born to mothers with COVID-19 reported three infants with pneumonia at birth who tested positive for viral RNA. Viral load was not measured and virus was detected only in samples taken two and four days after birth with subsequent samples testing negative ${ }^{12}$.

Asymptomatic infection by SARS-CoV-2 has been documented with levels of SARS-CoV-2 RNA in the respiratory tract comparable to those of COVID-19 patients ${ }^{4}$. Infection from 
asymptomatically infected people has been reported ${ }^{13,14}$. Thus, asymptomatic individuals may present the greatest risk of virus transmission to clinical staff. Almost all research has studied patients with overt symptoms and the presence of viral RNA in the blood, stool or reproductive organs of the asymptomatically infected is unknown. Whether patients with SARS-CoV-2 associated digestive symptoms shed infectious virus is also unknown ${ }^{15}$.

Given the evidence we have to date, a reasonable assumption would be that that the risk of SARS-CoV-2 transmission from laparoscopic surgery on the reproductive tract of a patient who is asymptomatic is likely to be low. Current guidance to United Kingdom blood donors is to refrain from donation for 14 days after exposure and if required to self-isolate. $A$ similar approach would likely limit the number of asymptomatically infected women undergoing gynaecological procedures. In symptomatic patients and patients who are known COVID-19 positive, the risk vs benefit of surgery will need to be evaluated on an individualised basis. Safe surgical practice and national infection protocols should be followed in all. More research measuring infectious virus in different clinical sample types is needed to drive evidence based practice.

\section{$\underline{\text { References }}$}

1. Joint Royal College of Obstetricians and Gynaecologists / British Society for Gynaecological Endoscopy statement of gynaecological laproscopic procedures and COVID-19. https://mkObritishsociep8d9m.kinstacdn.com/wpcontent/uploads/2020/03/Joint-RCOG-BSGE-Statement-on-gynaecologicallaparoscopic-procedures-and-COVID-19.pdf [accessed $8^{\text {th }}$ April 2020].

2. Updated Intercollegiate General Surgery Guidance on COVID-19. Issued by the Intercollegiate College of Surgeons. https://www.rcseng.ac.uk/-

/media/files/rcs/coronavirus/2nd-update-intercollegiate-general-surgery-guidanceon-covid19-6-april.pdf [accessed 8 th April 2020].

3. Wölfel R, Corman VM, Guggemos W, et al. Virological assessment of hospitalized patients with COVID-2019. Nature. 2020. Epub ahead of print.

4. Zou L, Ruan F, Huang M, et al. SARS-CoV-2 Viral Load in Upper Respiratory Specimens of Infected Patients. New England Journal of Medicine; 2020; 382:1177-1179.

5. Wang W, Xu Y, Gao R, et al. et al. Detection of SARS-CoV-2 in Different Types of Clinical Specimens. JAMA; 2020. Epub ahead of print.

6. Young BE, Ong SWX, Kalimuddin S, et al. Epidemiologic Features and Clinical Course of Patients Infected With SARS-CoV-2 in Singapore. JAMA; 2020. Epub ahead of print.

7. Chan JF, Yip CC, To KK, et al. Improved molecular diagnosis of COVID-19 by the novel, highly sensitive and specific COVID-19-RdRp/Hel real-time reverse transcriptionpolymerase chain reaction assay validated in vitro and with clinical specimens. J Clin Micro; 2020. Epub ahead of print.

8. Huang C, Wang Y, Li X, et al. Clinical features of patients infected with 2019 novel coronavirus in Wuhan, China. Lancet; 2020. 395:497-506.

9. Chen H, Guo J, Wang C, et al. Clinical characteristics and intrauterine vertical transmission potential of COVID-19 infection in nine pregnant women: a retrospective review of medical records. Lancet; 2020. 395:809-815.

10. Chen $\mathrm{Y}$, Peng $\mathrm{H}$, Wang $\mathrm{L}$, et al. Infants born to mothers with a new coronavirus (COVID-19). Frontiers in Pediatrics; 2020. 112:e254. 
11. Fan C, Lei D, Fang C, et al. Perinatal Transmission of COVID-19 Associated SARS-CoV2: Should We Worry? Clinical Infectious Diseases; 2020. Epub ahead of print.

12. Zeng L, Xia S, Yuan W, et al. Neonatal Early-Onset Infection With SARS-CoV-2 in 33 Neonates Born to Mothers With COVID-19 in Wuhan, China. JAMA Pediatr. 2020 Epub ahead of print.

13. Rothe C, Schunk M, Sothmann P, et al. Transmission of 2019-nCoV Infection from an Asymptomatic Contact in Germany. N Engl J Med. 2020; 382:970-971.

14. Chan JF, Yuan S, Kok KH, et al. A familial cluster of pneumonia associated with the 2019 novel coronavirus indicating person-to-person transmission: a study of a family cluster. Lancet. 2020; 395:514-523.

15. Han C, Duan C, Zhang S, et al. Digestive symptoms in COVID-19 patients with mild disease severity: clinical presentation, stool viral RNA testing, and outcomes. Am J Gastro. 2020. Epub ahead of print. 